\title{
Adsorption of chlorhexidine digluconate on acid modified fly ash: Kinetics, isotherms and influencing factors
}

\author{
Astha Singh, Sonalika Sonal, Rohit Kumar, Brijesh Kumar Mishra ${ }^{\dagger}$ \\ Department of Environmental Science and Engineering, Indian Institute of Technology (Indian School of Mines), Dhanbad-826004, India
}

\begin{abstract}
Chlorhexidine digluconate (CHD) in the aquatic environment causes irreversible change to microbes, making them resistant to biodegradation, which needs remediation other than biological process. Adsorption study was performed for the removal of CHD on fly ash (FA) as a function of $\mathrm{pH}$ and ionic strength. Experimental result has been validated by characterization using Scanning electron microscopy, Fourier Transform-Infrared Spectroscopy and Brunauer-Emmett-Teller. $\mathrm{CHD}$ adsorption with FA showed an increasing trend with an increase in $\mathrm{pH}$. Variation in $\mathrm{pH}$ proved to be an influential parameter for the surface charge of adsorbent and the degree of ionization of the CHD molecules. The adsorption capacity of CHD decreased from $23.60 \mathrm{mg}$ g-1 to $1.13 \mathrm{mg} \mathrm{g}-1$, when ionic strength increased from to $\mathrm{M}$. The adsorption isotherms were simulated well by the Freundlich isotherm model having R2 $=0.98$. The Lagergren's model was incorporated to predict the system kinetics, while the mechanistic study was better explained by pseudo-second order for FA. On the basis of operational conditions and cost-effectiveness FA was found to be more economical as an adsorbent for the adsorption of CHD.
\end{abstract}

Keywords: Adsorption, Chlorhexidine digluconate (CHD), Fly ash, Isotherm and Kinetics

\section{Introduction}

Among the water pollution issues, pharmaceutical and personal care product have attracted more and more attention as novel emerging contaminants by the scientific community and common public as well [1]. High pollution load to the aquatic ecosystem contains oodles of disinfectant and antibiotics such as Diclofenac, Naproxen, Ibuprofen, Sulfamethazine, Sulfamethoxazole, Sulfathiazole and Chlorhexidine Digluconate (CHD) [2]. The disposal and degradation of such persistent pollutants by natural means are a difficult attempt, although they affect water quality and potentially impact drinking water supplies [3]. CHD (Fig. S1) is cationic molecules [1,6-bis (4-chloro-phenylbiguanido) hexane], a widespread antimicrobial agent used extensively in dentistry and veterinary such as mouthwash, toothpaste, skin cleanser and some pre-operative skin preparation, frequently used in daily life. The widespread incorporation of $\mathrm{CHD}$ in a vast array of pharmaceutical and personal care product results in direct discharge into the aquatic environment after their use [4]. Presence of CHD in the aquatic system at higher and lower concentration reported as "bacteriostatic agent "and "bactericidal agent", making them resistant to biodegradation [5]. Stability of

This is an Open Access article distributed under the terms of the Creative Commons Attribution Non-Commercial License (http://creativecommons.org/licenses/by-nc/3.0/) which permits unrestricted non-commercial use, distribution, and reproduction in any medium, provided the original work is properly cited.

Copyright (C) 2020 Korean Society of Environmental Engineers
CHD molecules is also cramped due to its byproduct formation $p$-chloroaniline, which has rapid adsorption and metabolizing property, being hemotoxic and carcinogenic [6-7]. Therefore, the content of $p$-chloroaniline in mouthwash and the use of $\mathrm{CHD}$ at higher concentration limited by Pharmacopeias [8]. Moreover, CHD has been selected as a target compound due to its accumulation in the aquatic environment, affecting the aquatic life, sewage microorganisms as well as drinking water quality [6].

The mode of action and mechanism of pharmaceutical waste (PhW) and personal care products (PCPs) in the aquatic ecosystem is tremendously uncertain. They are pervasively connected to their action on molecules, cells, lymphatic organs and human health [6]. Composition and quantity of wastewater generated from the pharmaceutical industries play a crucial role in their treatment. Several treatment methods such as chemical oxidation, photolytic, photocatalytic treatment, biodegradation can be used to remove a wide array of pollutant generated from the pharmaceutical industry [9-11]. These treatment methods have some drawbacks such as high cost, generation of a residual or secondary pollutants or by-products, longer duration of treatment and insufficient removal efficiency, limiting the use of these treatment technologies [9].

Received November 232018 Accepted March 7, 2019

${ }^{\dagger}$ Corresponding author

Email: brijesh@iitism.ac.in

Tel: +91-9471191704

ORCID: 0000-0002-4451-1924 
Conversely, numerous favorable features of adsorption processes such as efficiency, simplicity, the capability of trace pollutant removal and no further by-product formation made it an alternative method for removal of PhW and PCPs. Adsorption could be easily scaled up from a laboratory to an industrial application with high removal efficiency [12-15].

The most commercialized adsorbent is activated carbon (AC) that has been used for the past few decades. But regeneration and cost effectiveness play a major role in the use of AC on large scale is difficult. Fly ash (FA) has received remarkable attention to overcome the cost-related problem. FA modified as a new low-cost AC due to its porosity, sphericity, high strength, non-toxicity and light weight property [16]. Use of FA as an adsorbent has dual benefit: i) removal of pharmaceutical and PCPs from the aquatic environment and ii) also maintaining the sustainability of the thermal power plant by-product generation [17]. Experimental pH and alkaline condition of wastewater generated from the pharmaceutical industry play a key role in the selection of adsorbent [18-19]. Easy availability of FA for the adsorption process prompts sustainable treatment technology as compared to the use of AC.

Adsorption of personal care product including CHD using traditional adsorbents (AC) has been well proved as it could not cause any by-product formation during adsorption, but the adsorption of compounds like $\mathrm{CHD}$ with $\mathrm{AC}$ needs $\mathrm{pH}$ modification of wastewater of pharmaceutical industry before adsorption process. The effluent from the pharmaceutical industry is well known for their alkaline nature and $\mathrm{pH}$ modification before treatment will cause economic and environmental complication. To overcome this issue the FA has been modified accordingly to achieve adsorption of $\mathrm{CHD}$ in alkaline condition. To understand the adsorption mechanism of modified FA, isotherm and kinetics studies were carried out and the property of adsorbent was examined by SEM, FTIR and Brunauer-Emmett-Teller (BET) analysis.

\section{Materials and Methods}

\subsection{Chemicals and Sample Preparation}

Standard solution of CHD $(20 \% \mathrm{w} / \mathrm{v})$ was purchased from Sigma-Aldrich. AC derived from charcoal, Sodium hydroxide $(\mathrm{NaOH})$, Hydrochloric acid $(\mathrm{HCl})$, Sodium chloride $(\mathrm{NaCl})$ was procured from Merck, India. Dissolved accurately weighed standard solution of CHD in $1 \mathrm{~L}$ of Milli-Q, RO water (Millipore, USA) to prepare $1,000 \mathrm{mg} \mathrm{L}^{-1} \mathrm{CHD}$ stock solution and serial dilution of the samples were carried for the lower concentration. FA was collected from Maithon Power Plant, Jharkhand.

\subsection{Adsorbent and Their Characterization}

In the present study, the FA was collected and sieved into a fine powder product and samples were washed number of times with warm distilled water ( $333.15 \mathrm{~K}$ ) to remove the impurities. Chemical washing of FA was performed by $10 \%$ concentrated sulfuric acid using vacuum filtration system followed by washing with distilled water and kept in the oven at $383.15 \mathrm{~K}$ for drying and activation before using it as an adsorbent [20]. The chemical constituents of FA having $\mathrm{SiO}_{2}$ (74.14\%), $\mathrm{Al}_{2} \mathrm{O}_{3}$ (22.77\%), $\mathrm{Fe}_{2} \mathrm{O}_{3}$ (1.244\%), $\mathrm{CaO}$
(1.19\%), $\mathrm{MgO}(0.612 \%)$, and $\mathrm{Na}_{2} \mathrm{O}(0.034 \%)$ was used in the present study. The BET surface area and porosity analyzer (Autosorb-1C, Quanta chrome, USA) were used to obtain surface area, pore size and pore volume under the influence of nitrogen gas at particular temperature $77.3 \mathrm{~K}$. The surface morphology and topography of the adsorbent were studied using a FESEM (Zessis, Germany). FTIR spectrophotometer (Perkin Elmer) was used to determine the presence of the functional groups on the surfaces of the adsorbent, participated in the adsorption process.

\subsection{Batch Experiment for Adsorption}

The adsorption experiments were carried out in $250 \mathrm{~mL}$ Erlenmeyer flasks by mixing $0.2 \mathrm{~g} \mathrm{~L}^{-1}$ of FA with $100 \mathrm{~mL}$ of pharmaceutical synthetic wastewater, containing different amount of CHD (ranging from $10 \mathrm{ppm}-500 \mathrm{ppm}$ ). The agitation speed of the mixture was maintained at $200 \mathrm{rpm}$ in orbital rotator shaker (Remi Shaker incubator, CIS-24 PLUS) at a range of 293.15-308.15 K for $60 \mathrm{~min}$. The $\mathrm{pH}$ (Hanna, India) of the solution was adjusted with $1 \mathrm{~N} \mathrm{NaOH}$ or $0.1 \mathrm{~N} \mathrm{HCl}$ solutions. The samples were then filtered through a filter paper (Whatman filter paper 42), and the concentration of $\mathrm{CHD}$ in the filtrate was estimated spectrophotometrically, at $275 \mathrm{~nm}$ using a UV-Vis spectrophotometer (Lab Tech 9100A, China).

$$
\% \text { Removal }=\frac{C_{i}-C_{t}}{C_{t}} \times 100
$$

Where, $C_{i}$ is the initial concentration of $\mathrm{CHD}$ in the solution (mg L $\left.{ }^{-1}\right), C_{t}$ is the concentration of $\mathrm{CHD}\left(\mathrm{mg} \mathrm{L}^{-1}\right)$ at time t.

$$
q_{e}=\frac{\left(C_{o}-C_{e}\right) V}{m}
$$

Where, $C_{o}$ is the initial concentration of $\mathrm{CHD}$ in the solution (mg L $\left.{ }^{-1}\right), C_{e}$ is the concentration of $\mathrm{CHD}\left(\mathrm{mg} \mathrm{L}^{-1}\right)$ at time $\mathrm{t}, V$ is the volume of solution (L) and $m$ is the mass of adsorbent (g), $q_{e}\left(\mathrm{mg} \mathrm{g}^{-1}\right)$ is the adsorption capacity at time $\mathrm{t}$.

\section{Results and Discussion}

\subsection{Selection of Adsorbent}

To understand the working $\mathrm{pH}$ during adsorption process, the "pHpzc" analysis was carried out for both the adsorbents and found 4.5 and 7.0 for AC and FA, respectively (Fig. S2 and S3). The "pHpzc" value for FA was found more favourable for adsorption of a selected pollutant, i.e. $\mathrm{CHD}$ as it has cationic property. The working $\mathrm{pH}$ of $\mathrm{FA}$ as an adsorbent was observed 8.5 which support the adsorption of $\mathrm{CHD}$ without further modification in the $\mathrm{pH}$ of wastewater. Keeping this fact, further study for AC was not investigated, and a detailed study was carried out with FA.

\subsection{Characterization of Adsorbent}

The surface morphology of the adsorbent before and after adsorption at the same magnification power has been shown in Fig. 1(a) \& (b). Large open pores, irregular and heterogeneous surface of adsorb- 


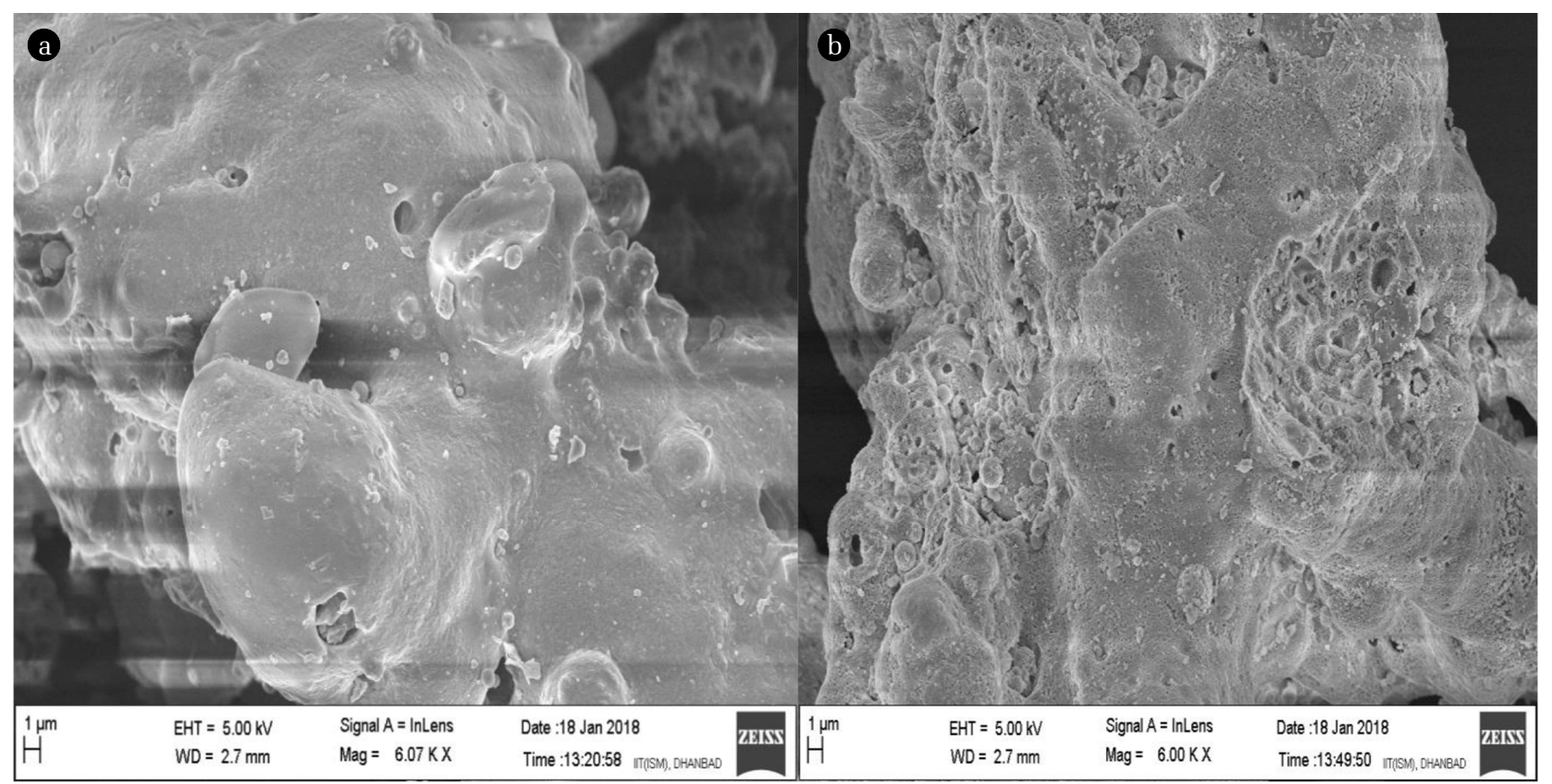

Fig. 1. Surface morphology of absorbent (a) before CHD adsorption and (b) after CHD adsorption; (FA).

ent before adsorption (Fig. 1(a)) supported the influencing characteristics of adsorbent material. However in Fig. 1(b), smooth surface morphology was observed after adsorption, which confirmed the adsorption process and deposition of the $\mathrm{CHD}$ on the adsorbent.

The specific surface area of FA was found $0.744 \mathrm{~m}^{2} \mathrm{~g}^{-1}$, respectively, using the BET equation. The classification of adsorbent pores were classified on the basis of their diameter into micropores ( $<2 \mathrm{~nm}$ ), mesopores (2-50 nm) and macropores (> $50 \mathrm{~nm}$ ) according to the International Union of Pure and Applied Chemistry (IUPAC) and the average pore width of FA was $2.3 \mathrm{~nm}$ ensuring it as a slightly mesoporous material due to unavoidable Vander Waal force [21]. This mesoporous structure of FA supported the accessibility of pollutants to the active sites, enhancing the adsorption process.

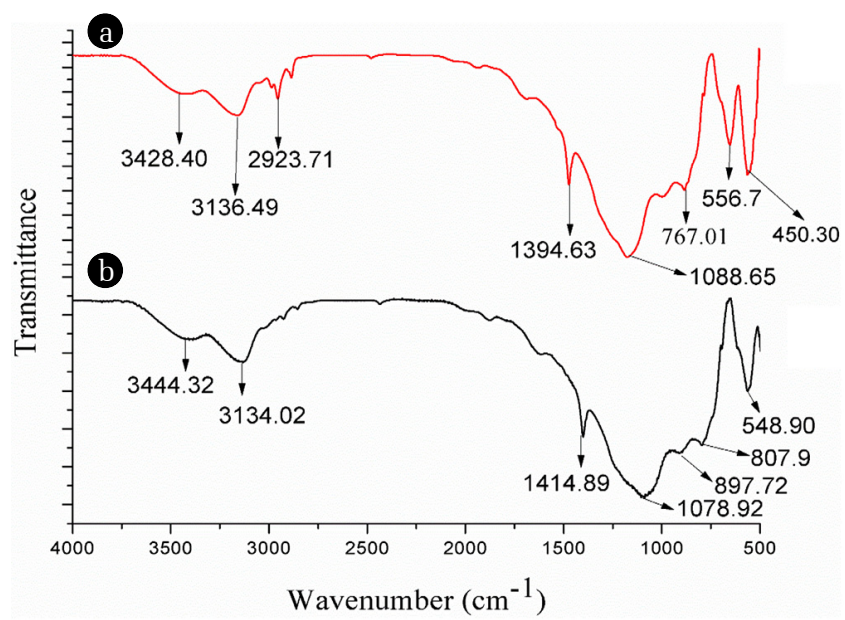

Fig. 2. Fourier Transform Infrared Spectroscopy of adsorption of CHD before and after onto (A) and (B) FA.
FTIR is a paramount technique to a qualitatively determine the functional group, which ensure the adsorption process. The FTIR spectra for FA before and after adsorption are shown in Fig. 2. The band observed at 1,088.65 $\mathrm{cm}^{-1}$ and $767.01 \mathrm{~cm}^{-1}$ before adsorption were assigned as quartz and $\alpha$ quartz, respectively, while the band near $450.30 \mathrm{~cm}^{-1}$ and $2,923.71 \mathrm{~cm}^{-1}$ ascribed as Si-O-Si bending and organic carbon, respectively in FA before adsorption, which confirms the basic properties of FA as an adsorbent [22-23]. The band within $800-400 \mathrm{~cm}^{-1}$ and $850-950 \mathrm{~cm}^{-1}$ ascribed as the occurrence of $\mathrm{C}-\mathrm{X}$ stretching and the $\mathrm{C}-\mathrm{H}$ stretching group in the organic compound [24]. There was a shift in the bands after adsorption of CHD on FA in the range of 800.7-897.72 $\mathrm{cm}^{-1}$ revealed that the adsorption process of CHD on FA. Lastly, the band present at $1,414.89 \mathrm{~cm}^{-1}$ in FA after adsorption has been ascribed to the presence of hydrocarbon revealing sorption of $\mathrm{CHD}$ over FA [16].

\subsection{Effect of $\mathrm{pH}$ on $\mathrm{CHD}$ Adsorption}

Experimental results revealed that the maximum removal efficiency of $\mathrm{CHD}$ was $77.5 \%$ at $\mathrm{pH} 8.5$ as shown in Fig. 3(a). To optimize the removal percentage and $\mathrm{pH}$, adsorption experiment was conducted in the $\mathrm{pH}$ range of 2.5-10.5 and the removal percentage varied from $13.67 \%$ to $77.23 \%$ as shown in Fig. 3(a). The result indicated that dissociation constant and $\mathrm{pH}$ play a crucial role in the adsorption of $\mathrm{CHD}$ onto FA, as dissociation of $\mathrm{CHD}$ molecules can be affected with change in $\mathrm{pH}$. CHD molecules are expected to be protonated at $\mathrm{pH}<\mathrm{P}_{\mathrm{ka}}\left(\mathrm{P}_{\mathrm{ka}}=10.8\right)$, which dominates the cationic form of CHD in solution and $\mathrm{pH}>$ "pHpzc" ("pHpzc" of FA $=7.0$ ), also confirmed the negative charge on the surface of FA. The results revealed that the adsorption capacity increased due to electrostatic interaction among highly protonated CHD molecules and negatively charged FA [25]. The FA comprised of metal 
oxide that forms an aquo complex with water, and negative charge density on surface of adsorbent increased at $\mathrm{pH}>$ "pHpzc" of FA, which would further increase the removal efficiency due to the electrostatic interaction, whereas acidic medium $(\mathrm{pH}<$ "pHpzc") does not favor the removal of cationic adsorbate species as dissociation of CHD molecules suppressed by the presence of $\mathrm{H}^{+}$[26]. Conversely, as $\mathrm{pH}$ increased the amino group of CHD molecules are protonated, and the surface of adsorbents were deprotonated, which attributed more adsorption of $\mathrm{CHD}$ at moderately alkaline condition due to the electrostatic interaction between the positively charged adsorbate and negatively charged adsorbent [25].

\subsection{Effect of Ionic Strength on CHD Adsorption}

The adsorption capacity of CHD onto FA was significantly decreases from $23.60 \mathrm{mg} \mathrm{g}^{-1}$ to $1.13 \mathrm{mg} \mathrm{g}^{-1}$, when ionic strength increased from $1 \times 10^{-3}$ to $5 \times 10^{-1} \mathrm{M}$ as shown in Fig. 3(b). According to the literature, electrical double layer present around the surface of an adsorbent and CHD molecules which supports the binding of adsorbate to the adsorbent due to electrostatic interaction [27]. Compression of double layer occurs with an increase in ionic strength of the solution which reduces the thickness of the double layer according to the theory on diffuse double layer given by Gouy-Chapman. The gradual decrease in the adsorption capacity of FA was observed when the ionic strength increased; this might be due to competition between counter ions or consequent compression of electrical double layer present on the surface of FA due to electrostatic interaction made by chloride ion that further leads to more adherence of $\mathrm{CHD}$ with the water molecules [28-30]. Therefore, increase in the concentration of $\mathrm{NaCl}$ increased the bonding between $\mathrm{CHD}$ and FA, this leads to decrease in the adsorption of $\mathrm{CHD}$ by pairing their charges, and this initiated the adsorbent to sorb more positive CHD ions [31].

However, FA showed maximum adsorption at $\mathrm{pH} 8$ with an increased concentration of ions. This indicates that at $\mathrm{pH} 8$, the effect of $\mathrm{pH}$ is predominant compared to ionic strength due to the cationic form of $\mathrm{CHD}$ and negatively charged surface of the adsorbent. This leads to a very high electrostatic attraction between $\mathrm{CHD}$ and adsorbent. A similar work about the effect of ionic strength on the adsorption of personal care product on different adsorbent was observed [31].

\subsection{Isotherm Study of CHD}

The adsorption isotherm studies provide significant information of adsorption capacity, adsorption properties and affinity of the adsorbent. Adsorption experiments have been performed at a constant dose, $\mathrm{pH}$ and time, whereas the initial concentration of the pollutant was varied. Two isotherm models namely Langmuir and Freundlich models were applied to examine the adsorption equilibrium by non-linear modelling. Non-linearized form of the Langmuir and Freundlich model can be written as following equations [32].

$$
\begin{aligned}
q_{e} & =\frac{Q_{o} b C_{e}}{1+b C_{e}} \\
q_{e} & =K_{F} C_{e}^{1 / n}
\end{aligned}
$$

Where, the equilibrium concentration of $\mathrm{CHD}\left(\mathrm{mg} \mathrm{L}^{-1}\right)$ is defined by $\mathrm{C}_{\mathrm{e}}, q_{e}$ is the amount of $\mathrm{CHD}$ adsorbed at equilibrium $\left(\mathrm{mg} \mathrm{g}^{-1}\right)$, $Q_{o}$ is the maximum monolayer adsorption capacity of adsorbent $\left(\mathrm{mg} \mathrm{g}^{-1}\right)$ and $b$ is the Langmuir adsorption constant $\left(\mathrm{L} \mathrm{mg}^{-1}\right), K_{f}$ and $n$ are the Freundlich constants incorporating the factor affecting adsorption intensity and adsorption capacity, respectively. The Langmuir and Freundlich isotherm plots discussed in Fig. 4 showed the relationship between the equilibrium constant $\left(\mathrm{C}_{\mathrm{e}}\right)$ and adsorption capacity $\left(q_{e}\right)$ due to $\mathrm{CHD}$ uptake of prepared aqueous solution for FA at $303.15 \mathrm{~K}$. The graph plots among experimentally calculated values of $1 / q_{e}$ versus $1 / C_{e}$ (Langmuir isotherm), $\log q_{e}$ versus Log $\mathrm{C}_{\mathrm{e}}$ (Freundlich isotherm) at different temperature were made using origin pro 8.5.0SRI and best-fit values of parameters were determined. The values of the isotherm
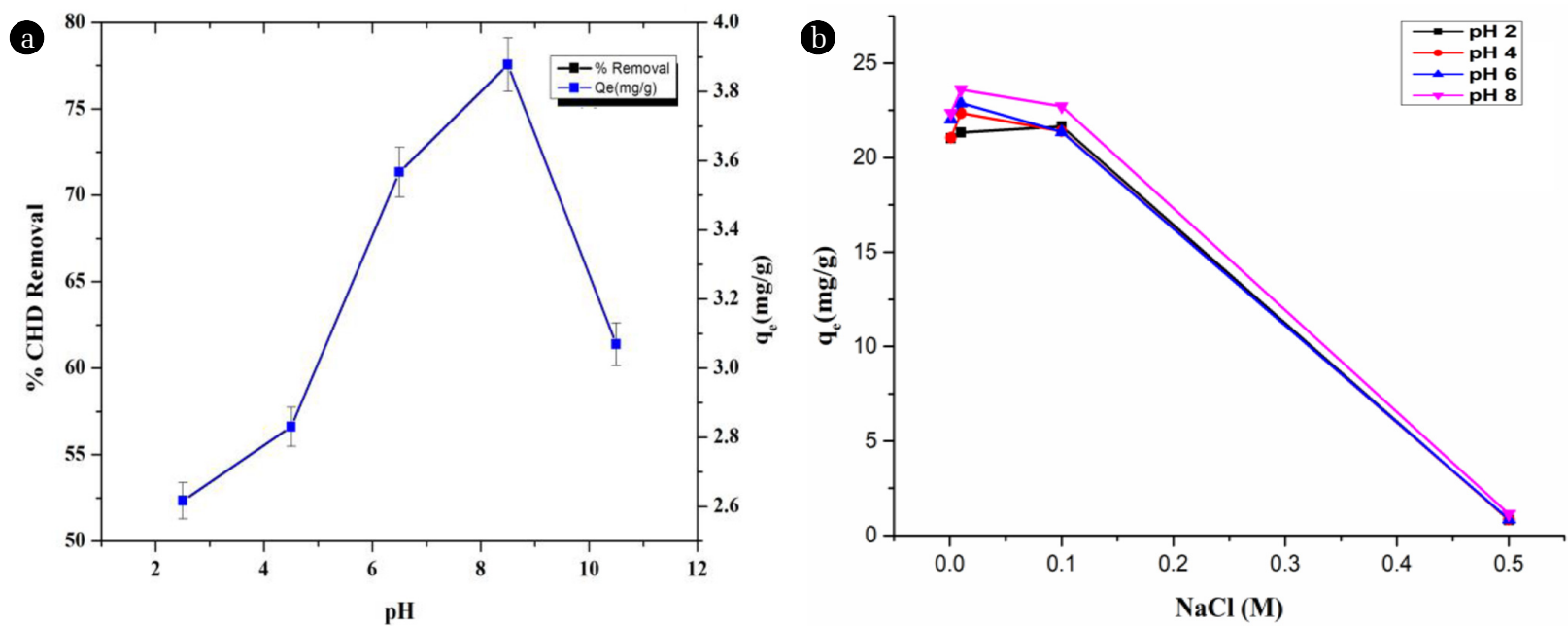

Fig. 3. Effect of solution (a) $\mathrm{pH}$ and (b) Effect of ions on $\mathrm{CHD}$ adsorption onto $\mathrm{FA}\left(\mathrm{C}_{0}=10 \mathrm{mg} / \mathrm{L}\right.$, adsorbent dose $\left.=0.2 \mathrm{~g} / \mathrm{L}\right)$. 

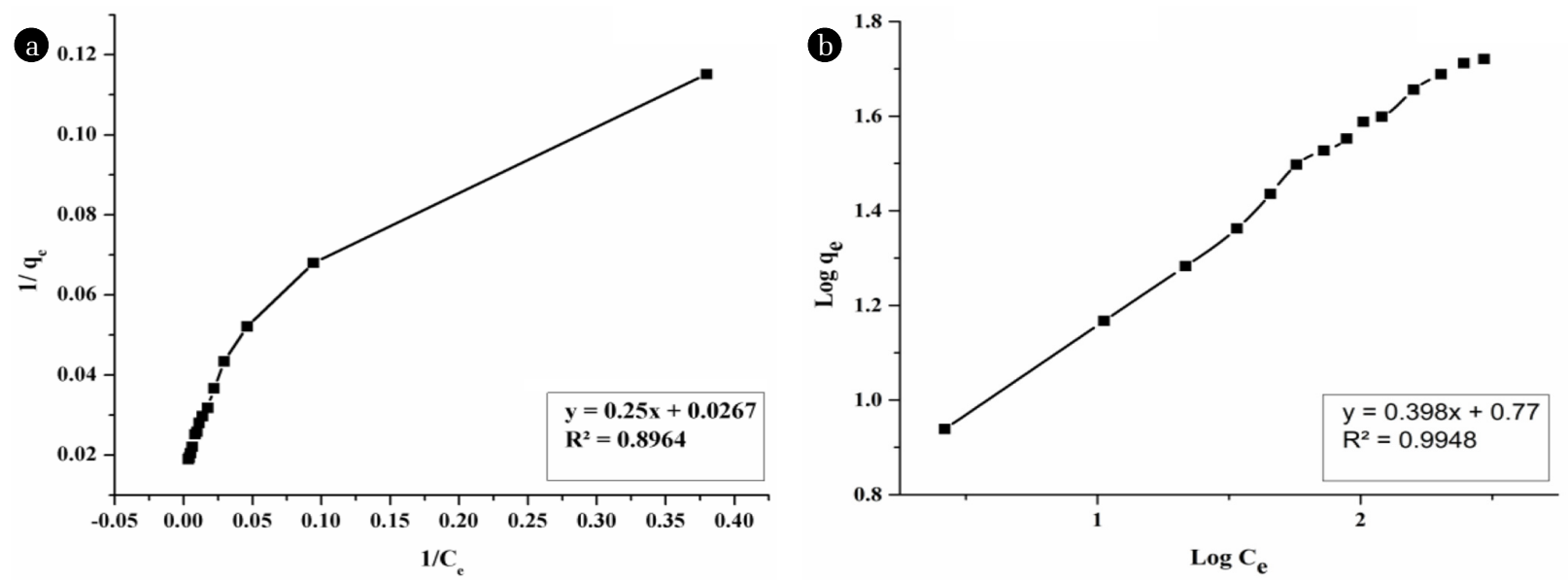

Fig. 4. Plot of $\mathrm{C}_{\mathrm{e}}$ versus $\mathrm{q}_{\mathrm{e}}$ (a) Langmuir; (b) Freundlich isotherm of $\mathrm{CHD}$ adsorption on fly ash at $303.15 \mathrm{~K}$.

Table 1. Calculated Isotherm Parameters for Langmuir and Freundlich Models for Adsorption of Chlorhexidine Digluconate onto Fly Ash at Various Temperature

\begin{tabular}{|c|c|c|c|c|c|c|c|}
\hline \multirow{2}{*}{ Adsorbent } & \multirow{2}{*}{ Temperature $\left({ }^{\circ} \mathrm{C}\right)$} & \multicolumn{3}{|c|}{ Langmuir isotherm } & \multicolumn{3}{|c|}{ Freundlich isotherm } \\
\hline & & $\mathbf{Q}_{\mathrm{m}}$ & $\mathbf{K}_{\mathbf{L}}$ & $\mathbf{R}^{2}$ & $\mathbf{K}_{\mathbf{f}}$ & $\mathbf{n}$ & $\mathbf{R}^{2}$ \\
\hline \multirow{4}{*}{ Fly ash } & $20^{\circ} \mathrm{C}$ & 19.7 & 17.5 & 0.58 & 5.5 & 2.2 & 0.59 \\
\hline & $25^{\circ} \mathrm{C}$ & 61.3 & 0.012 & 0.92 & 2.4 & 1.4 & 0.96 \\
\hline & $30^{\circ} \mathrm{C}$ & 47.01 & 0.0334 & 0.91 & 5.5 & 2.4 & 0.98 \\
\hline & $35^{\circ} \mathrm{C}$ & 30 & 0.0048 & 0.90 & 2.45 & 2.15 & 0.90 \\
\hline
\end{tabular}

constants and correlation coefficient, $\mathrm{R}^{2}$ for the best-fit of the equations have been listed in Table 1.

The regression coefficient $\left(\mathrm{R}^{2}\right)$ is deemed to serve as a reliable statistical metric for the determination of quality fitness from the data obtained from applying an isotherm model [22]. Furthermore, the regression coefficient $\left(\mathrm{R}^{2}\right)$ also serves as a reliable metric for comparing the efficacy of different isotherm models. It was observed that the Freundlich model $\left(\mathrm{R}^{2}=0.98\right)$ showed a better regression coefficient than the Langmuir model, thus ascertaining adsorption of $\mathrm{CHD}$ onto FA, for all the temperatures. This showed the heterogeneous distribution of CHD on the active site of adsorbent and thus leads to multilayer formation [22]. From the models (both Langmuir and Freundlich), a consistent affinity towards the adsorption of $\mathrm{CHD}$ on FA was deduced from the test for Freundlich isotherm.

\subsection{Kinetic Studies of CHD}

The kinetic model used to establish the adsorption mechanisms as well as possible rate controlling steps and equilibrium concentration as a function of time. The kinetics of the adsorption system was studied using pseudo-first order [33] and pseudo-second order [34], expressed as:

$$
\begin{gathered}
\ln \left(q_{e}-q_{t}\right)=\ln q_{e}-k_{i} t \\
t / q_{t}=\frac{1}{k_{2} q_{e}{ }^{2}}+\frac{1(t)}{q_{e}}
\end{gathered}
$$

Where, $q_{e}$ is the amount of CHD adsorbed at equilibrium (mg $\mathrm{g}^{-1}$ ) and $q_{t}$ is the amount adsorbed at time $\mathrm{t}$ and the constant rate for pseudo-first order sorption $\left(\mathrm{min}^{-1}\right)$ is denoted by $k_{i}$. The kinetic parameter for these two models was calculated from Eq. (5) or (6). From Fig. 5 and calculated parameter in Table 2, the kinetic rate was well simulated by the pseudo-second order having $\mathrm{R}^{2}$ value 0.93 . The results revealed that the adsorption of $\mathrm{CHD}$ onto FA was dominated by the pseudo-second order model,

Table 2. Parameters for Two Kinetic Model of CHD Adsorption

\begin{tabular}{lccc}
\hline Adsorbent & Model & Parameter & Value \\
\hline & Pseudo-first order: $\ln \left(q_{e}-q_{t}\right)=\ln q_{e}-k_{1} t$ & $k_{1}\left(\mathrm{~min}^{-1}\right)$ & 0.075 \\
\cline { 2 - 4 } Fly ash & Pseudo-second order: $\frac{t}{q_{t}}=\frac{1}{k_{2} q_{e}{ }^{2}}+\frac{1(t)}{q_{e}}$ & $R_{2}\left(\mathrm{mg} / \mathrm{g} / \mathrm{min}^{-1}\right)$ & 0.8671 \\
\cline { 2 - 4 } & & $R^{2}$ & 0.182 \\
\hline
\end{tabular}



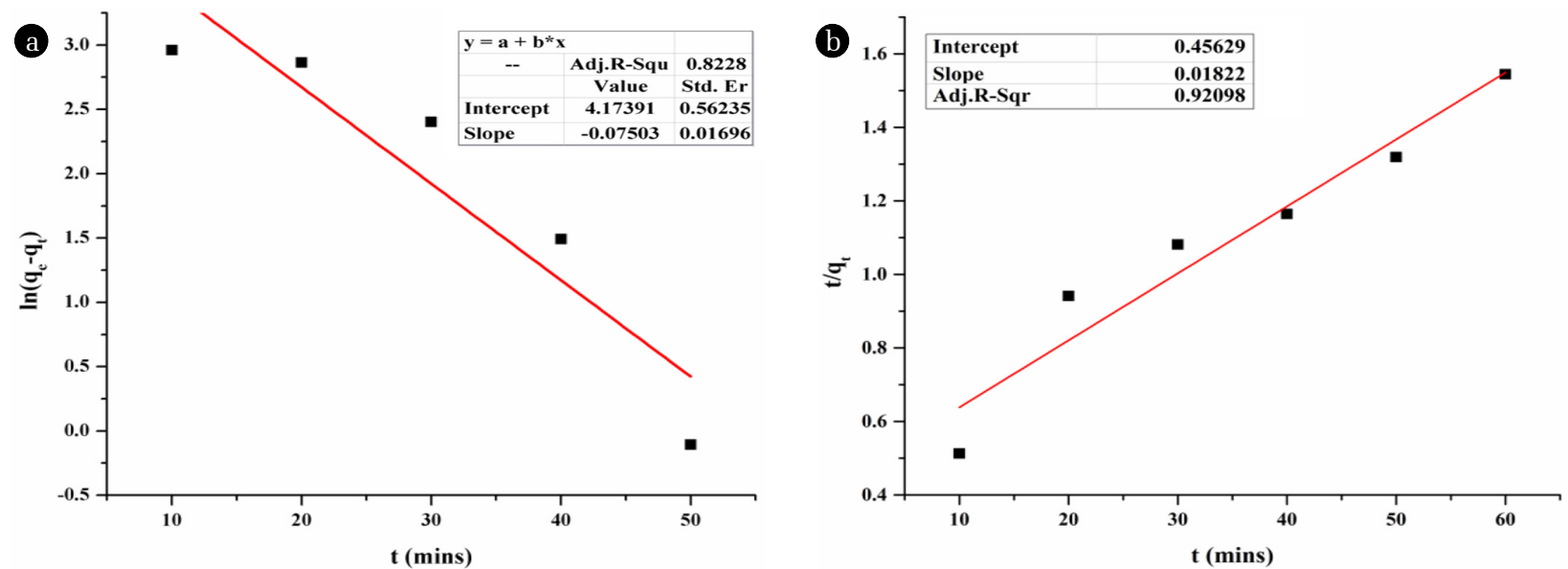

Fig. 5. Fitting curves of (a) pseudo-first order kinetic model and (b) pseudo-second order for FA dosage of $0.2 \mathrm{~g} / \mathrm{L}$ at; $\mathrm{pH}-8.5$, CHD concentration $-50 \mathrm{mg} / \mathrm{L}$ for $60 \mathrm{~min}$.

which indicating that chemisorption involving valance force through the exchange or sharing of electrons controlled the adsorption rate [35].

\subsection{Regeneration Study}

Regeneration capacity is one of the important criteria for the selection of adsorbent and to understand the stability of the selected adsorbent, i.e. FA. The regeneration study was carried out, and a significant amount of $\mathrm{CHD}(60.08 \%)$ desorption was observed after the third cycle. Considering FA as an adsorbent for the removal of $\mathrm{CHD}$ from aqueous solution showed promising regeneration potential of the selected adsorbent.

\section{Conclusions}

The $\mathrm{H}_{2} \mathrm{SO}_{4}$-activated FA showed a good adsorption capacity for $\mathrm{CHD}$ removal in alkaline conditions. The experimental data were best described by the Freundlich isotherm model with the highest $\mathrm{R}^{2}$ value (0.98), which confirmed the multilayer of the adsorbent surface. The kinetic study suggested that the pseudo-second order model was best fitted for FA and indicated the chemisorption mechanism for the adsorption process. The influence of ionic strength on the population of functional adsorbent sites shows proportionate participation in the ion-exchange of $\mathrm{CHD}$ compounds on modified FA. Overall, the favorable operational conditions during the adsorption process of FA could be the best choice for controlling the transport of $\mathrm{CHD}$ and other personal care product similar to $\mathrm{CHD}$ in the aquatic environment.

\section{Acknowledgments}

The authors would like to acknowledge Indian Institute of Technology (Indian School of Mines), Dhanbad, India, for providing research and financial facilities. The authors declare no conflict of interest.

\section{References}

1. Khraisheh M, Kim J, Campos L, et al. Removal of pharmaceutical and personal care products (PPCPs) pollutants from water by novel $\mathrm{TiO}_{2}$-Coconut Shell Powder (TCNSP) composite. J. Ind. Eng. Chem. 2014;20:979-987.

2. Gopakumar KM, Santosh MR. An unhealthy future for the Indian pharmaceutical industry? 3rd World Resurgence 2012;259:9-14.

3. Fent K, Weston AA, Caminada D. Ecotoxicology of human pharmaceuticals. Aquat. Toxicol. 2005;76:122-159.

4. Sousa CP, de Oliveira RC, Freire TM, et al. Chlorhexidine digluconate on chitosan-magnetic iron oxide nanoparticles modified electrode: Electroanalysis and mechanistic insights by computational simulations. Sens. Actuat. B. Chem. 2017;240:417-425.

5. Das R, Ghosh S, Bhattacharjee C. A green practice for pharmaceutical drug chlorhexidine digluconate treatment and ecotoxicity assessment. J. Water Process Eng. 2015;7:266-272.

6. Kroemer G, Galluzzi L, Vandenabeele P, et al. Classification of cell death: Recommendations of the nomenclature committee on cell death. Cell Death Differ. 2009;16:3-11.

7. Zong Z, Kirsch LE. Studies on the instability of chlorhexidine. Part I: Kinetics and mechanisms. J. Pharm. Sci. 2012;101: 2417-2427.

8. Nidhi K, Indrajeet S, Khushboo M, Gauri K, Sen DJ. Hydrotropy: A promising tool for solubility enhancement: A review. Int. J. Drug Dev. Res. 2011;3:26-33.

9. Rivera-Utrilla J, Sánchez-Polo M, Ferro-García MÁ, Prados-Joya G, Ocampo-Pérez R. Pharmaceuticals as emerging contaminants and their removal from water. Chemosphere 2013;93:1268-1287.

10. Akhtar J, Amina NAS, Shahzad K. A review on the removal of pharmaceuticals from water by adsorption. Desalin. Water Treat. 2016;57:12842-12860.

11. Dalrymple OK, Yeh DH, Trotz MA. Removing pharmaceuticals and endocrine-disrupting compounds from wastewater by photocatalysis. J. Chem. Technol. Biotechnol. 2007;82:121-134.

12. Moral-Rodríguez AI, Leyva-Ramos R, Ocampo-Pérez R, Mendoza-Barron J, Serratos-Alvarez IN, Salazar-Rabago JJ. Removal of ronidazole and sulfamethoxazole from water sol- 
utions by adsorption on granular activated carbon: Equilibrium and intraparticle diffusion mechanisms. Adsorption 2016;22: 89-103.

13. Gholamreza Moussavi, Rasoul Khosravi. Removal of cyanide from wastewater by adsorption onto pistachio hull wastes: Parametric experiments, kinetics, and equilibrium analysis. J. Hazard. Mater. 2010;183:724-730.

14. Eletta OAA, Ajayi OA, Ogunleye OO, Akpan IC. Adsorption of cyanide from aqueous solution using calcinated eggshells: Equilibrium and optimization studies. J. Environ. Chem. Eng. 2016;4:1367-1375.

15. Deng Y, Li B, Yu K, Zhang T. Biotransformation and adsorption of pharmaceutical and personal care products by activated sludge after correcting matrix effects. Sci. Total Environ. 2016;544:980-986

16. Patra G, Barnwal R, Behera SK, Meikap BC. Removal of dyes from aqueous solution by sorption with fly ash using a hydrocyclone. J. Environ. Chem. Eng. 2018;6:5204-5211.

17. Zhang A, Wang N, Zhou J, Jiang P, Liu G. Heterogeneous Fenton-like catalytic removal of p-nitrophenol in water using acid-activated fly ash. J. Hazard. Mater. 2012;201-202:68-73.

18. Rahele Rostamian, Hassan Behnejad. A comprehensive adsorption study and modeling of antibiotics as a pharmaceutical waste by graphene oxide nanosheets. Ecotoxicol. Environ. Saf. 2018;147:117-123.

19. Harja M, Ciobanu G. Studies on adsorption of oxytetracycline from aqueous solutions onto hydroxyapatite. Sci. Total Environ. 2018;628-629:36-43.

20. Shah AK, Ali ZM, Laghari AJ, Farman S, Shah A, Pollutants W. Utilization of fly ash as low-cost adsorbent for the treatment of industrial dyes effluents-A comparative study. J. Eng. Technol. 2013;2:1-10.

21. Gaber D, Abu Haija M, Eskhan A, Banat F. Graphene as an efficient and reusable adsorbent compared to activated carbons for the removal of phenol from aqueous solutions. Water Air. Soil Pollut. 2017;228:320.

22. Mohan D, Singh KP, Singh G, Kumar K. Removal of dyes from wastewater using flyash, a low-cost adsorbent. Ind. Eng. Chem. Res. 2002;41:3688-3695.
23. Clara Jeyageetha J, Sugirtha P Kumar. Study of SEM/EDXS and FTIR for fly ash to determine the chemical changes of ash in marine environment. Int. J. Sci. Res. 2016;5:ART2016554.

24. Barbara Stuart. Infrared Spectroscopy: Fundamentals and Applications. New Jersey: John Wiley \& Sons; 2004.

25. Sarkar S, Bhattacharjee C, Curcio S. Studies on adsorption, reaction mechanisms and kinetics for photocatalytic degradation of $\mathrm{CHD}$, a pharmaceutical waste. Ecotoxicol. Environ. Saf. 2015;121:154-163.

26. Stafiej A, Pyrzynska K. Adsorption of heavy metal ions with carbon nanotubes. Sep. Purif. Technol. 2007;58:49-52.

27. Belmouden M, Assabbane A, Ichou YA. Adsorption characteristics of a phenoxy acetic acid herbicide on activated carbon. J. Environ. Monit. 2000;2:257-260.

28. Hu Y, Guo T, Ye X, et al. Dye adsorption by resins: Effect of ionic strength on hydrophobic and electrostatic interactions. J. Chem. Eng. 2013;228:392-397.

29. Wang S, Ma Q, Zhu ZH. Characteristics of coal fly ash and adsorption application. Fuel 2008;87:3469-3473.

30. Boumediene M, Benaïssa H, George B, Molina St, Merlin A. Effects of $\mathrm{pH}$ and ionic strength on methylene blue removal from synthetic aqueous solutions by sorption onto orange peel and desorption study. J. Mater. Environ. Sci. 2018;9:1700-1711.

31. Behera SK, Oh SY, Park HS. Sorption of triclosan onto activated carbon, kaolinite and montmorillonite: Effects of $\mathrm{pH}$, ionic strength, and humic acid. J. Hazard. Mater. 2010;179:684-691.

32. Foo KY, Hameed BH. Insights into the modeling of adsorption isotherm systems. Chem. Eng. J. 2010;156:2-10.

33. Lin J, Wang L. Comparison between linear and non-linear forms of pseudo-first-order and pseudo-second-order adsorption kinetic models for the removal of methylene blue by activated carbon. Frontiers Environ. Sci. Eng. China 2009;3:320-324.

34. Subramanyam B, Das A. Study of the adsorption of phenol by two soils based on kinetic and isotherm modeling analyses. Desalination 2009;249:914-921.

35. Cochrane EL, Lu S, Gibb SW, Villaescusa I. A comparison of low-cost biosorbents and commercial sorbents for the removal of copper from aqueous media. J. Hazard. Mater. 2006;137: 198-206. 